wlenever it was taken. After ineffectual trials of various preparations of quinin with the same disastrous results he decided to place the patient under the influence of morphin ples atropin. Under the influence of these drugs he tranquilly injected up to 15 grains of quinin without further dis. turbances, which promptly arrested the threatening symp. toms."

In 1902, I pubished an arti"le on "Difficulties in, and the Management of, Pernicious Malarial Fevers, with and Without Idiosyncrasy for Quinin" in the Mobile Medical and sur gical Joumal. This article was copied in several other medical periodicals. The special point to which attention was called in the paper is the solving of this therapentical prob. lem by the administration of morphin plus atropin alone, prior to giving quinin.

I also wish to direct attention to the value of administering thymol in large doses, in punctured eapsules, in amebic dyseitery.

This mention is suggestew by the article. "Medical versus Suruical Treatment of Amebic Dysentery" in THE Jovrxal, December 19. The administration of the thymol capsules $\mathbf{m}$ - be preceded by a dose of magnesium sulphate; 20 grains of thymol are administered every two hours until three doses are given. The thymol capsules are withheld until active purging is begun and if necessary are followed by a saline purge. This treatment is repeated every second or third day, or at longer intervals according to the patient's tolerance. If necessary, this treatment may be followed by bismuth and npiates. On the day when the thymol is not given by the month, high colonic irrigations of thymol solution are given. Fluid diet is given throughout the treatment.

This line of treatment proved promptly effective in two serious cases in $m y$ practice and the patients have resumed work, which they had been unable to do for five or six years. Reports from these patients show increase of weight and apparent recovery, though in neither case were subseguent microseopic examinations made. As instructions were given to repeat the treatment once every week or oftener if symptoms returned. I can not assert a positive cure. I think that a report of the value of this method may lead others to investigate it in order to determine its ultimate value, and it may prove preferable to appendicostomy with irrigation.

G. H. Fonde, M.D., Mobile, Ala.

LComment: Apparently Nogara had never heard of the use of morphin with quinin in malaria, as he states in his article that he thought of it, but hesitated at first to try it as he had no opportui.ity to experiment with it.-ED.]

\section{Local Applications in Appendicitis}

To the Editor:-Under the above heading in The Joursal, June 27,1908, p. 2121 , there appeared an article by Dr. J. E. Moore, in which the use of the ice bag in acute appendicitis was referred to as the height of folly and as post-hoc reasoning.

For years $I$ have used ice applications (preferably drain ice bags) extensively in hospital and private practice, in many acute ailments, including selected cases of acute appendicitis, and at no time has injury been observed to the regions where such applications were made.

No ice-bag application of ordinary size and kind can cause freezing of the parts applied, because the living tissues inrolved can never be cooled to or under the freezin? point, as the ice is constantly in a melting and not freezing state (in an ordinary atmosphere with the temperature about $70 \mathrm{ks}$.$) .$

No one, of course, would use freezing mixtures, nor use such a large amount of ice as to cause a possible damage by weight, in obstructing the circulation of the parts.

It is not cor"ect to say that the therapeutic effect of ice application is only superficial or skin deep. The application of jee to the human bod means the exposure of such parts to forms of heat rays, that is to mo'ecular and ethereal vibrations peculiar to ice in a state of liquefaction. These heat ray's penetrate different media according to their nature. Some media are poor conductors, some are good. The living, human body affords no great barrier to these "ice-rays." They are transmitted by direct continuity of tissues exposed.

Necessarily, ice applications have their limitations. The period of elimination, when established, may demand their prompt removal, the use of drugs or the surgeon's knife. But, it should be understood, that it is "no post-hoe reason. ing" nor "height of folly" to employ en ice-bag in the proper wa and at the proper time,

Even many cases of acute appendicitis demand it and it should be considered negligence and poor treatment not to use it.

P. A. Aurness, M.D., Minneapolis.

\section{Book Notices}

Tue Srxual Question. By August Forel, M.D., Ph.D., II.D., formerly Professor of Psychiatry at and Director of the Insane Asylum in Zurich (Switzerland). Fnglish translation by C. F. Marshall, M.D. F.R.C.S. Late Assistant Surgeon to the Hospital for Diseases of the Skin. London. Pp. 536.
Cloth. I'rice, $\$ 3.00$. New York: Rebman Co.

This is an elaborate sociologic treatise that commands attention because of its fearlessness and its manifest humanity, however much some may be displeased at Forel's cynicism concerning religion. Few of us can study a sociologic subject without being greatly influenced by our habitual acceptance of many, at least, of the established dogmas of custom, society, law and religion, but this need not prevent our welcoming to the literature of this problem the contribution of one who, for purposes of absolute freedom of deduction, has attempted to disregard these dogmas.

The first part of the book is concerned with a simple and plain exposition of genesis, embryology, coitus, pregnancy, sexual characteristics and sexual appetite. Then broadening out, Forel discusses love and its irradiations, distinguishes between love and sexual impulse, and shows the various relations of both emotions to procreative instinct, jealousy, prudery, modesty, desire for domination, religion, etc. He here shows the extent of his study and the breadth of his altruism, bringing out many points that need to be borne in mind by physicians, educators, judges and in fact, by all who have dealings with their fellow men.

Then follow chapters on ethnology and history, sexual selection, sexual evolution and sexual pathology. These are refreshingly sane and free from the flippant vulgarity and unnecessary detail sometimes indulged in by writers whose familiarity with the subjects of which they write has made them forget not only the state of mind of some into whose hands the book will fall, but also their alleged purpose in writing the book. Wherever we may disagree with Forel, we must agree that he has a clean mind.

Now the book takes up the more sociologic side of the question, discussing its relation to money, property, alcohol, environment, religion, law, society, prostitution, means of preventing conception, politics, pedagogy and art. Forel proposes this general axiom: The coitus of two individuals, performed with mutual deliberation and causing no harm to a third person, shonld be considered as a private affair, and should have no connection with either civil or penal law. Here Forel takes a stand in opposition to custom, morals, law and religion, but it is not so bad as it sounds at first, for the third person proviso is really a very broad exception. The "third person" represents society and Forel is outspoken in the declaration that the good of society is a higher law than the right of the individual. It is interesting to note his mode of harmonizing these two demands-the rights of society and the rights of the individual-in his application of the general axiom above quoted to the problems presented by inverts and harmless perverts, whose acts are punishable under the laws of many lands. "The real crime," he declares, "is the marriage of an invert to an individual of the opposite sex, and yet this crime is sanctioned by the law!" Similarly he urges immunity trom legal punishment for those forms of bestiality that are free from eruelty, as he is unatle to see harm in them and as the relief afforded by them protects women and children (i. e., society) from attack by these perverts. 